\title{
A multiscale texture analysis procedure for improved forest stand classification
}

\author{
C. A. COBURN \\ Department of Geography, The University of Lethbridge, Lethbridge, \\ Alberta, Canada, T1K 3M4; e-mail: craig.coburn@uleth.ca
}

and A. C. B. ROBERTS

Department of Geography, Simon Fraser University, Burnaby, British Columbia, Canada, V5A 1S6

(Received 26 June 2003; in final form 17 December 2003)

\begin{abstract}
Image texture is a complex visual perception. With the everincreasing spatial resolution of remotely sensed data, the role of image texture in image classification has increased. Current approaches to image texture analysis rely on a single band of spatial information to characterize texture. This paper presents a multiscale approach to image texture where first and secondorder statistical measures were derived from different sizes of processing windows and were used as additional information in a supervised classification. By using several bands of textural information processed with different window sizes (from $5 \times 5$ to $15 \times 15$ ) the main forest stands in the image were improved up to a maximum of $40 \%$. A geostatistical analysis indicated that there was no single window size that would adequately characterize the range of textural conditions present in this image. A number of different statistical texture measures were compared for this image. While all of the different texture measures provided a degree of improvement (from 4 to 13\% overall), the multiscale approach achieved a higher degree of classification accuracy regardless of which statistical procedure was used. When compared with single band texture measures, the level of overall improvement varied between 4 and $8 \%$. The results indicate that this multiscale approach is an improvement over the current single band approach to analysing image texture.
\end{abstract}

\section{Introduction}

The visual interpretation of remotely sensed data has always relied on image spatial properties to separate image components into similar groups (Lillesand and Kiefer 2000). This visual process takes advantage of an interpreter's ability to perceive spatial and tonal differences rapidly and group areas with similar spatial structure with little ambiguity (Franklin et al. 2001). Statistical classification procedures have been successful at separating spectral classes from digital remotely sensed data based on their spectral properties alone. These classification techniques have been most successful at classing areas from images with relatively low spatial resolutions (i.e. orbital satellite data). However, at high spatial resolutions, an area that was formerly spectrally uniform will be composed of pixels with a higher 
degree of spectral variation. Furthermore, areas of complex terrain (e.g. mountainous terrain) or more complex class structures associated with many emerging environmental applications may not be adequately classified using standard perpixel classifiers operating on image tone alone (Peddle 1995).

The incorporation of spatial variation (image texture) in image classification procedures is an increasingly important aspect of high spatial resolution remotely sensed data analysis. Several studies have addressed this difficulty by calculating a single spatial variable and adding it to a classification procedure. Overall improvement in classification accuracy indicates that the addition of image texture improves image classification (Jensen 1982, Franklin and Peddle 1987, 1989, 1990, Cohen et al. 1990, Peddle and Franklin 1991, Gong et al. 1992, Franklin and McDermid 1993, Ryherd and Woodcock 1996, Wulder et al. 1998, Franklin et al. 2001).

There are several standard approaches to texture processing. Recent research has focused on texture measures derived from moving a fixed-size, odd-numbered window through the image and calculating a variety of different pixel relationships (Lillesand and Kiefer 2000). By far the most prevalent technique used for deriving texture measures is the use of the grey-level co-occurrence matrix (GLCM). This technique uses a spatial co-occurrence matrix that computes the relationships of pixel values and uses these values to compute the second-order statistical properties from these matrices (Haralick 1979, Hsu 1980, Jensen 1982, Franklin and Peddle 1987, 1989, 1990, Peddle and Franklin 1991, Barber and LeDrew 1991, Miranda et al. 1992, Franklin and McDermid 1993, Jensen 1996).

The use of local image variation as a measure of texture has received relatively little interest in the remote sensing community, compared with the use of GLCMs. In one of the only studies to compare various techniques used for calculating textural properties, Weszka et al. (1976) state that first- and second-order statistics performed in a similar manner. The main difference is the simplicity of the firstorder calculations compared with the complexity of the second-order statistical calculations. More recently, measurements of local variance have been used to provide a measure of texture in studies involving simulated images or lowresolution satellite imagery (Woodcock and Strahler 1987, Dobbertin and Biging 1996, Ryherd and Woodcock 1996, Collins and Woodcock 1999).

Geostatistical analysis has proved to be an essential tool for analysing the spatial dependence of remotely sensed data. Many studies have demonstrated the efficacy of this suite of quantitative techniques for estimating the optimum spatial resolution for remotely sensed data (Curran 1988, Atkinson 1993), and they have also been used as a tool to model the spatial variation within images (Woodcock et al. 1988b, St-Onge and Cavayas 1995, Wulder et al. 1996, 1998). In this study, the relationship between local image variance and semivariance was used to demonstrate that image variance, used in a multiscale approach, is an alternative measure of image texture. This approach to image texture analysis provided a measure of image texture that is simple to compute and was able to characterize textural information as well as more complex methods.

\section{Image texture}

Spatial information is more difficult to quantify than spectral information as it involves measurements of variability, pattern, shape and size. Of all the spatial information that can be extracted from remotely sensed data, texture may be the most useful for segmenting images. Due to the importance of image texture for 
separating areas many different approaches to extracting textural information have been developed. Texture has always been a primary visual cue for defining areas and relates to the visual perception of coarseness or smoothness of image features. When defined in a quantitative sense, texture is a property that relates to the nature of the variability of pixel values. A visually smooth texture would contain only slight changes in digital number (DN) values over an area while a visually coarse texture would contain many abrupt changes in DN values over an area (Haralick 1979). Digital definitions of texture are, therefore, a surrogate for the visual perception of texture.

There are many different methods used to extract textural information from images. These approaches can be characterized as structural, model-based and frequency-based. Structural approaches to texture analyses are based on the theory that textures are composed of repeating elements called primitives (Haralick 1979). Hay and Niemann (1994) presented a structural method for analysing texture from forested scenes. While the results of their study indicated a good correspondence between the classes and the ground data, the structural method is limited because of the amount of information that is required to adequately characterize texture (Hay and Niemann 1994).

Model-based approaches attempt to find stochastic processes that are able to model texture (Cross and Jain 1983). These techniques (Markov random fields, fractal models and autoregressive models) have had success in analysing microtextures but they are not as useful for macro-textures, situations where little is known about the texture, or more than one texture exists (deSouza 1982, Mao and Jain 1992).

Feature-based texture analysis derives texture measures directly from the image. This approach to texture analysis relies on spatial information derived from local operators, statistical attributes and from the examination of images in the frequency domain (Van Gool et al. 1985, DuBuf et al. 1990, Reed and DuBuf 1993). This method of texture processing is the most diverse and commonly implemented approach to image texture processing. The main focus of remote sensing research on texture analysis and classification has involved the use of second-order statistics derived from the grey-level co-occurrence matrix (Haralick 1979, Hsu 1980, Jensen 1982, Franklin and Peddle 1987, Barber and LeDrew 1991, Miranda et al. 1992, Franklin and McDermid 1993, Jensen 1996, Franklin et al. 2001). Relatively few studies have focused on the use of lower-order statistical properties of images (Weszka et al. 1976, Woodcock and Strahler 1987, Dobbertin and Biging 1996, Ryherd and Woodcock 1996, Collins and Woodcock 1999).

\subsection{Statistical analysis of image texture}

Statistical procedures used to analyse image texture can be separated by level of measurement. First-order statistics are used to characterize statistical properties such as average, standard deviation, mode or variance within an area. Other statistical approaches include the texture spectrum (Wang and $\mathrm{He} \mathrm{1990),} \mathrm{and}$ frequency-based contextual classifiers (Wharton 1982, Gong and Howarth 1992, Eyton 1993). These statistical procedures analyse the properties of the distribution over areas, are efficient to calculate and provide useful information about the pixel neighbourhood under consideration.

Second-order statistics seek to characterize the changes in the distribution of pixel values over space by describing the mutual dependence of sets of pixels. It is 
this property that has led to their use for the analysis of texture as image texture (Julesz 1962, Haralick et al. 1973). The most popular second-order statistics for texture processing are those calculated from the grey-level co-occurrence matrix (GLCM) and measure a number of properties relating to the relationships between pairs of pixels in a neighbourhood.

The texture spectrum approach of Wang and He (1990) is based on computing pixel relationships from a $3 \times 3$ window. This technique compares the centre pixel to each of the neighbouring pixels and records three logical relationships (smaller, equal, greater). The summation of this neighbourhood produces a texture value. Using this technique there are a total of 6561 possible relationships that make up the texture spectrum (Wang and $\mathrm{He} 1990$ ). Xu et al. (2003) modified the original texture spectrum procedure to include only the closest four pixel values, decreasing the number of possible combinations and increasing the efficiency of the procedure with similar results.

The use of variance as a measure of texture has received relatively little attention in the remote sensing community, compared with the use of GLCMs. In one of the only studies to compare various techniques used for calculating textural properties, Weszka et al. (1976) stated that first- and second-order statistics performed in a similar manner. The main difference was the simplicity of the first-order calculations compared with the complexity of the second-order statistical calculations. More recently, measurements of local variance have been used to provide a measure of texture in studies involving simulated images or lowresolution satellite imagery (Woodcock and Strahler 1987, Dobbertin and Biging 1996, Ryherd and Woodcock 1996, Collins and Woodcock 1999, Franklin et al. 2001). A few studies have compared the different techniques to evaluate the differences between the approaches to developing spatial variables (Weszka et al. 1976, Haralick 1979).

\subsection{Geostatistics}

Geostatistical analysis techniques have grown in popularity for analysing remotely sensed data. One of the most promising techniques is the implementation of variograms to remotely sensed data as a means of classifying image texture (Curran 1988, Jupp et al. 1988, Woodcock et al. 1988a, b, Lark 1996, Chica-Olmo and Abarca-Hernandez 2000). While several studies have shown that semivariance is useful for quantifying texture, few studies have assessed semivariance as a tool for mapping image texture (Schachter et al. 1978, Miranda et al. 1992).

Variograms have been used to quantitatively estimate the optimum spatial resolution for remotely sensed data (Curran 1988, Atkinson 1993). In a similar manner, they have also been used as a tool to model the spatial variation within images (Woodcock et al. 1988b, St-Onge and Cavayas 1995, Wulder et al. 1998, Treitz 2001).

All statistical approaches to texture analysis require a method to define the size of the convolution filter window. The size of the filter window is important as it defines the area used for statistical calculations. Several studies have used geostatistical tools, specifically the variogram, to describe the magnitude of variation (sill) and the extent of spatial dependence (range) (Curran 1988, Woodcock et al. 1988a, b). More recent research has found that range values are useful for determining the maximum size of processing windows or limits to spatial resolution (Cohen et al. 1990, Franklin and McDermid 1993, Wulder et al. 1998). 


\section{Image data collection and study areas}

\subsection{Imaging system}

The remotely sensed data were acquired using the Simon Fraser University airborne remote sensing system and aircraft (Roberts 1995). This system can be configured in a number of different modes to capture photographic or electrooptical images. For this research, the electro-optical imaging system was used. This system was composed of three Sony XC-7500 progressive-scan digital cameras that produce an image 659 columns by 494 rows with square pixels $(9.9 \times 9.9 \mu \mathrm{m})$. The signal from the Sony XC-7500 cameras was digitized using an Everex 32-bit analogue-to-digital conversion board. For this research the spatial resolution of the image produced was 4 metres.

These cameras were configured with a filtration set-up designed to replicate colour infrared film. The specific filters used were the Kodak 88A (720-850 nm), Nikon R60 (585-665 nm) and the Nikon X1 (490-565 nm). Exposure control for the electro-optical system was performed by flying over the brightest target area and adjusting the camera's lens aperture (f-stop) to provide the optimum exposure for that area with the assistance of a waveform monitor. Most electro-optical camera systems have an automatic adjustment for controlling sensor gain (automatic gain control or AGC). This feature was disabled, as it will adjust the exposure of the sensor once a threshold over- or under-exposure setting is reached. More information on the electro-optical system can be found in Roberts (1995).

\subsection{Study area}

Ben Lake $\left(52^{\circ} 35^{\prime} \mathrm{N} 122^{\circ} 05^{\prime} \mathrm{W}\right)$ is located in the Interior Plateau region of British Columbia, Canada (figure 1). This region is characterized by relatively flat to rolling topography formed in glacial deposits, with a relatively dry climate receiving approximately $40 \mathrm{~cm}$ of precipitation per year (British Columbia Commission on Resources and Environment 1994). The area contains a mixed Douglas fir (Pseudotsuga menziesii) and lodgepole pine (Pinus contorta var. latifolia) forest interspersed with stands of regenerated lodgepole pine.

Ground data were gathered for this site for classification accuracy assessment. These reference data were compiled from field observations, existing forest cover maps and photographic interpretation of the aerial image data. These data were then combined to produce a reference map that was used as the relative measure of 'truth' for each area (figure 2).

Field data were collected as close to the imaging date as possible. As the size of the study area was relatively small, detailed investigations of the forest stands were possible. Data on the species composition, age and stand density were recorded from a number of sample plots within each tree stand. Several plots were used to provide a reliable estimate of the conditions present for each stand (table 1).

There were three different forest stands present in the image. The region is dominated by mixed Douglas fir and lodgepole pine stands that are on average 100 years old and between 28 and 38 metres in height. These two dominant stands have a slightly different species composition mix and have different stand densities (table 1). The younger lodgepole pine stand in the area is regenerated and, therefore, does not display the diversity of the older stand. 

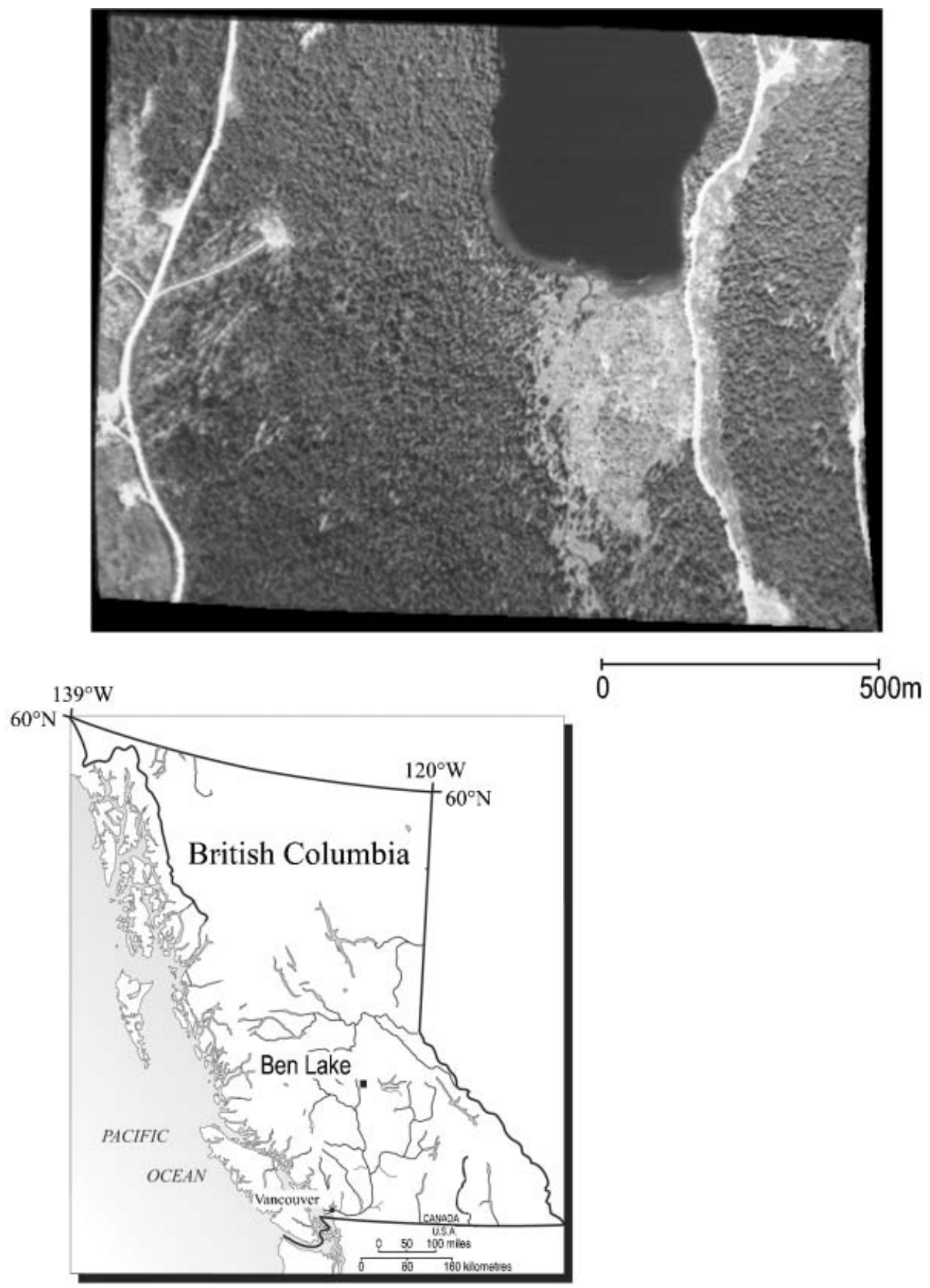

Figure 1. Ben Lake study site. This image was acquired with the electro-optical imaging system and has a ground resolution of 4 metres.

\subsection{Processing}

For this study, a geostatistical analysis was conducted to characterize the image textural differences and to establish the spatial parameters (window size) used to derive texture variables. This analysis was used to derive the area over which the 

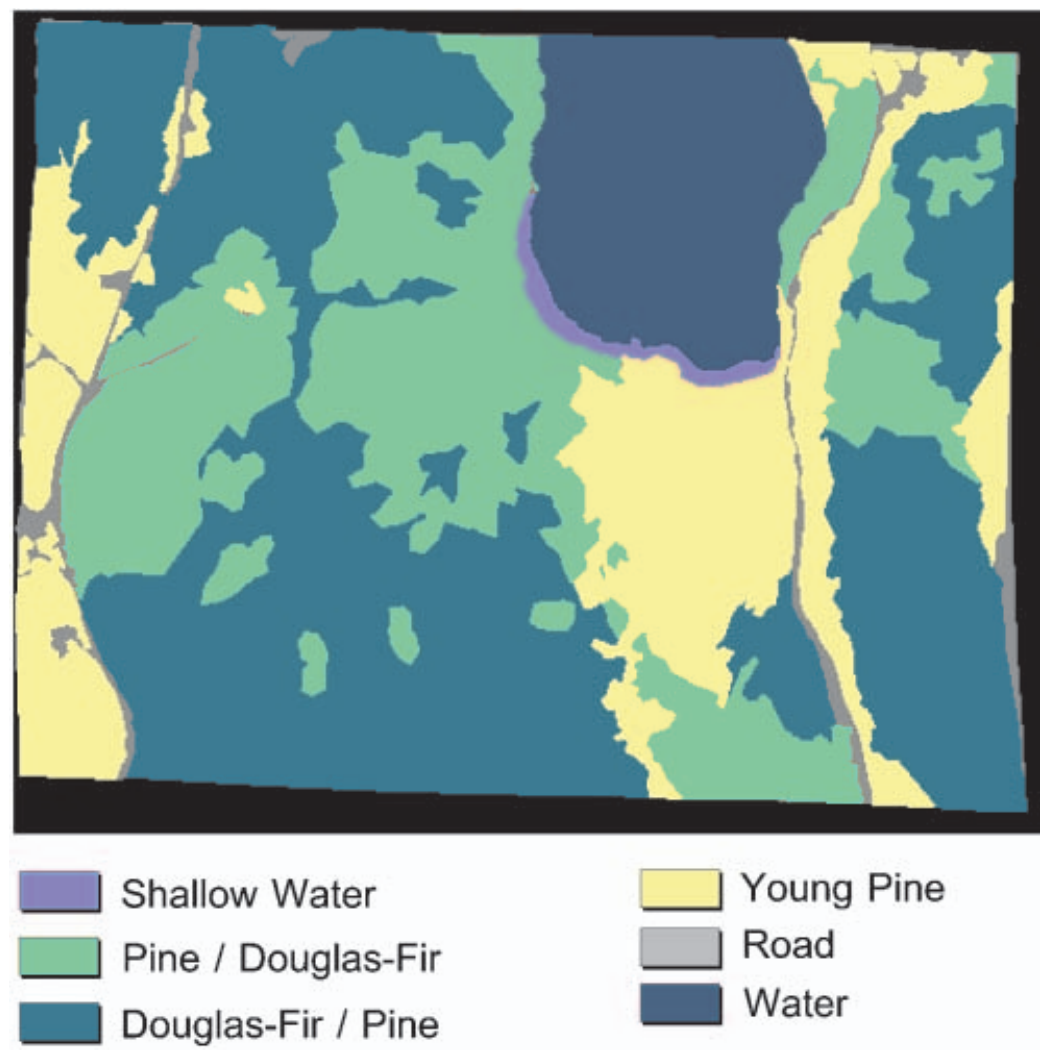

Figure 2. The ground data map produced from field observations and visual interpretation.

texture was measured (range) and the amount of variation for each test area (sill). The image was then processed using both variance measures and GLCM techniques to assess the utility of the multiscale procedure.

\subsubsection{Geostatistical data generation}

Geostatistical data analysis was conducted on selected test areas extracted from each image. The selection of the test areas was conducted in the same fashion as the collection of training field data for supervised classification: for example, areas with visually similar image textures were selected on-screen in the same fashion that spectrally similar groups are defined in the training process with classical multispectral supervised classification (Lillesand and Kiefer 2000).

The test areas were selected to represent the range of spatial variability present for all visually identifiable texture groups within the image. Unlike spectral

Table 1. Summary table of information gathered from field investigation of the Ben Lake image. All values are averages taken from a number of sites for each stand.

\begin{tabular}{lcccc}
\hline & Species mix & Age (years) & Height (m) & Stems hectare $^{-1}$ \\
\hline Douglas fir, lodgepole pine & $60-40$ & $100-140$ & $28-38$ & 2250 \\
Lodgepole pine, Douglas fir & $55-45$ & $100-140$ & $28-38$ & 1500 \\
Lodgepole pine & 100 & $10-20$ & $3-5$ & 1850 \\
\hline
\end{tabular}


sampling, the size of the area under investigation is critical for geostatistical investigations. In this study, the maximum number of points (1000) that the geostatistical software package (Variowin 2.2) could process were used as the size of the area under investigation. It should be noted that this limitation is a function of the software and not the technique (Pannatier 1996).

Variograms can be measured in individual directions, or for all directions (omnidirectional). The latter approach was used in this research to more closely replicate variance measured within a window. The other reason for not measuring semivariance with respect to a specific orientation was that, if there were a strong directionality to the semivariance, the area would display a pattern of dominant regularity. While pattern and texture are related, this research was focused on texture. If areas showed a dominant direction to their spatial variability then they are exhibiting pattern not texture.

To determine the values of semivariance at intermediate distances, a curve was fitted to the semivariance points. This curve is the modelled variogram and was used to determine the sill and range values. The spherical model was selected as it produced the best fit for the experimental variogram.

\subsubsection{Texture processing}

For this research two different approaches to texture processing were utilized, local variance and second-order statistics derived from a spatial co-occurrence matrix. Window sizes from $5 \times 5$ to $15 \times 15$ were used to process the textural information from the image. Local image variation is a simple measure of dispersion from the mean within the processing neighbourhood. The result of this procedure is an image dataset that contains the variance values for all spectral bands for the given window size. For each increasing window size (from $5 \times 5$ to $15 \times 15$ ) a new image dataset was created. The maximum size of the processing window was set using the range values from the geostatistical analysis. The dynamic range of the data used for this research was not altered. Data from the imaging system was quantized at 8-bit resolution while the variance data were represented as 32-bit data.

Image texture was also analysed using second-order statistics from a GLCM using the same window sizes $(5 \times 5$ to $15 \times 15)$. In this study, three second-order texture measures were selected: angular second moment, entropy and contrast. Angular second moment measures homogeneity and is smallest when all of the GLCM probabilities are similar and largest when they are different. Entropy is a measure of the amount of order and repeatability, and contrast is a measure of the degree of spread of the values in the matrix (Haralick 1979, Sali and Wolfson 1992). The image data used for computing the GLCM measures were not altered from the original 8-bit data from the image capture card.

\subsubsection{Classification}

A standard maximum likelihood classification routine was used to classify all of the images produced in this study. The training fields used in this supervised classification procedure were identical for all of the classifications produced. A series of classifications were produced for each of the four different texture measures (local variance, angular second moment, entropy and contrast). Classifications were conducted for each of the different window sizes from $5 \times 5$ 
to $15 \times 15$, as well as a classification that utilized all of the window sizes and one classification that only incorporated the texture fields.

\subsubsection{Accuracy assessment}

Classification accuracy assessment was used to compare the effect of using additional texture measures in the image classifications. Overall correct classification provided a measure of agreement between the classifications produced and the ground data map on a pixel-by-pixel basis. A kappa analysis was also conducted to include the off-diagonal elements in the analysis.

One of the shortcomings of the confusion matrix approach is that the accuracy assessment does not provide a direct measure of specific class improvement or degradation between the different classifications. For this research, the kappa index of agreement (KIA) was used to compare the specific class differences between the classifications. This index measures the association between two images on a category-by-category basis. The values produced vary from -1 to 1 for each category (group) in the image. If the input images are in perfect agreement then KIA equals 1 ; if there is no agreement then KIA equals - 1 . If the difference is produced by chance then KIA equals 0 (Rosenfield and Fitzpatrick-Lins 1986).

The assessment of classification accuracy is an important step in any image classification procedure. Sometimes, methods used to assess classification accuracy can result in the over-estimation of the accuracy of the classification (Rosenfield and Fitzpatrick-Lins 1986). For this research, the changes that resulted from the addition of different texture measures were evaluated by comparing error matrices from the different classifications. These matrices express the number of pixels that are in agreement between the classed map and the ground data. To remove potential sampling bias in the results, all pixels in the image were evaluated.

This full-image approach to accuracy assessment is not usually used for applied remote sensing because it requires a detailed set of ground data (Lillesand and Kiefer 2000). While no map represents every group with absolute precision or accuracy, comparing all images to the same ground data map does provide a common and consistent measure for comparison between the different classifications produced.

\section{Results}

\subsection{Variance-semivariance relationship}

Figure 3 shows the sill values for all of the major forest stands for all three spectral bands. While all areas showed different degrees of variation for each spectral band, the infrared band was selected as it showed the greatest degree of variation for the spectral bands in this study. Figure 4 represents the variograms for the infrared band for the three main forest stands in the image. The pine/Douglas fir class had the greatest spatial variation while the younger pine group showed the least spatial variation.

The differences in the sill values suggested that there were different degrees of spatial variability (texture) between the groups. When the variance values for each successively larger window are extracted and plotted, they showed a similar trend to that of the variograms. Figure 5 shows the average variance measured for successively larger window sizes for each area. The magnitude of the measures was different because one measure was a difference from the mean (variance) and the other was an absolute difference measure (semivariance). 


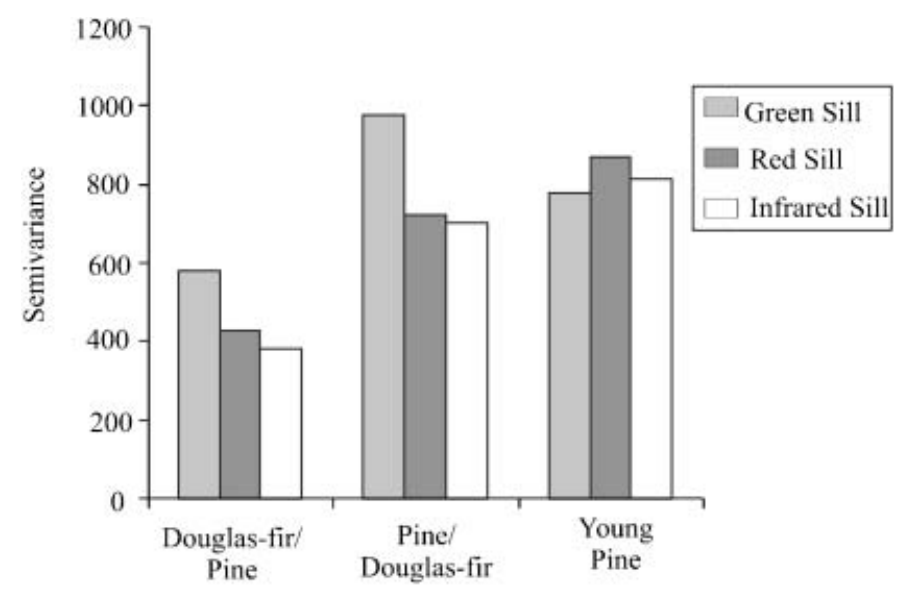

Figure 3. Ben Lake image sill values for the major forest stands for all three spectral bands. The difference in sill values indicated that there were differences in texture between bands.

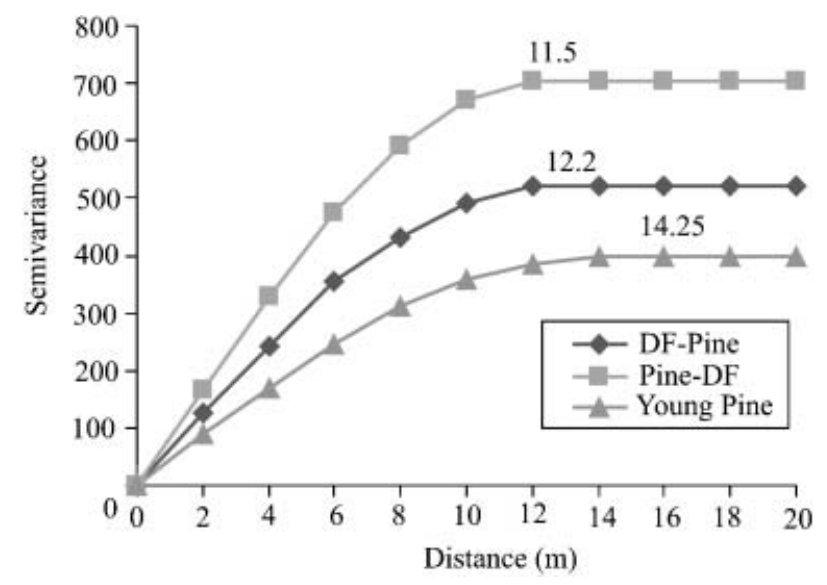

Figure 4. Variograms computed from the infrared band for the major forest types. Range values are indicated above each line.

\subsection{Classification results}

Figure 6 shows the supervised classification results using only the spectral information. This classification is typical of classifications produced from high spatial resolution data in forested environments. The contingency table (table 2) shows that the overall correct classification for this image was $61.24 \%$ and the majority of the error in classification was between the different forest stands (table 2).

While some of the groups were easily separated (water and road for example), the main forest stands (Douglas fir/pine and pine/Douglas fir) were difficult to separate as these classes represent differences in species mix (table 1) not differences in tone. The correct classification of these two groups required the additional spatial information provided through the addition of image texture in order to improve the accuracy of the image classification.

The geostatistical analysis indicated that the optimum window size for analysing 


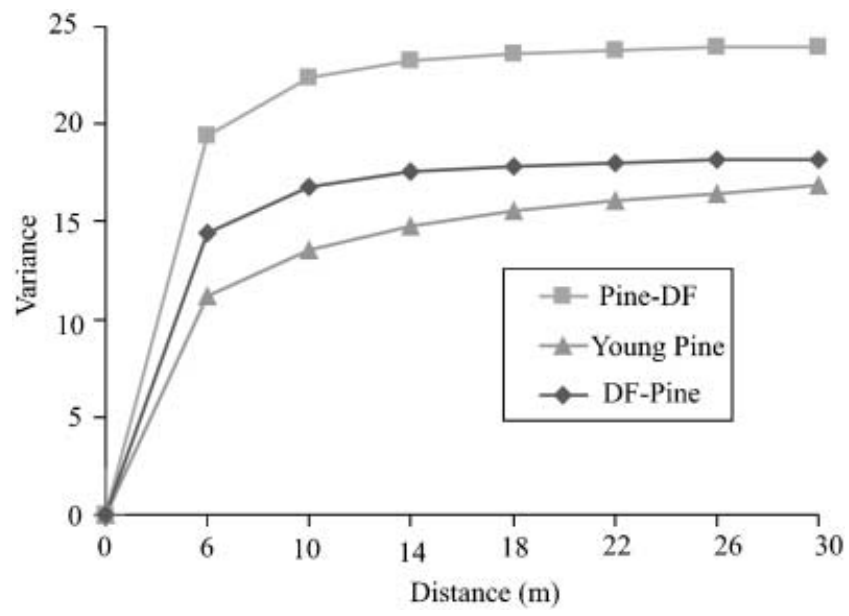

Figure 5. Multiscaled variance graphs for the Ben Lake image. The shape of the curves are similar indicating that variance measured over distance can function as an analogue to semivariance measures.

these data was between $11 \times 11$ and $15 \times 15$ (figure 3 ). Using each of the different measures of image texture, an additional band of information was incorporated into the image classification. Classifications were produced with image texture measured with window sizes from $5 \times 5$ to $15 \times 15$.

\subsubsection{Local variance results}

Figure $6(b)$ is the classification produced by including local variance computed within a $5 \times 5$ window and shows that the addition of local variance improved the visual appearance of the classification of smoother areas (young pine). Table 3 shows the contingency table for this classification and shows that the forest stands received the greatest benefit from the addition of texture with improvements between 4 and $15 \%$.

As the window size was increased there was a further improvement in the classification accuracy of the forest stands areas (figure 7(a)), but areas with lower degrees of variation (water for example) displayed growth effects caused by the size of the filter which decreased the accuracy of the classification for this group (table 4). This demonstrated that there was not a single processing window that was able to adequately characterize all the textures for this image.

In the multiscale procedure, all of the variance data (from $5 \times 5$ to $15 \times 15$ ) were used for a single spectral band (infrared in this example). Figure $7(b)$ shows the resulting classification. While similar in appearance to the classification produced with the larger window sizes $(13 \times 13,15 \times 15)$ it displayed less 'edge-effect'. For example, while the water area continued to decrease in size, it did not decrease to the same degree with the multiscale approach.

For the majority of the classes, the classification accuracy increased with increasing variance window sizes, with the highest degree of accuracy being attained by the multiscale classification procedure. The overall correct classification for the spectral classification was $61.24 \%$ while the multiscale classification was $74.59 \%$, an increase of approximately $13 \%$. The difference in the Khat statistic was even greater, with an improvement of $19 \%$ (table 5). 


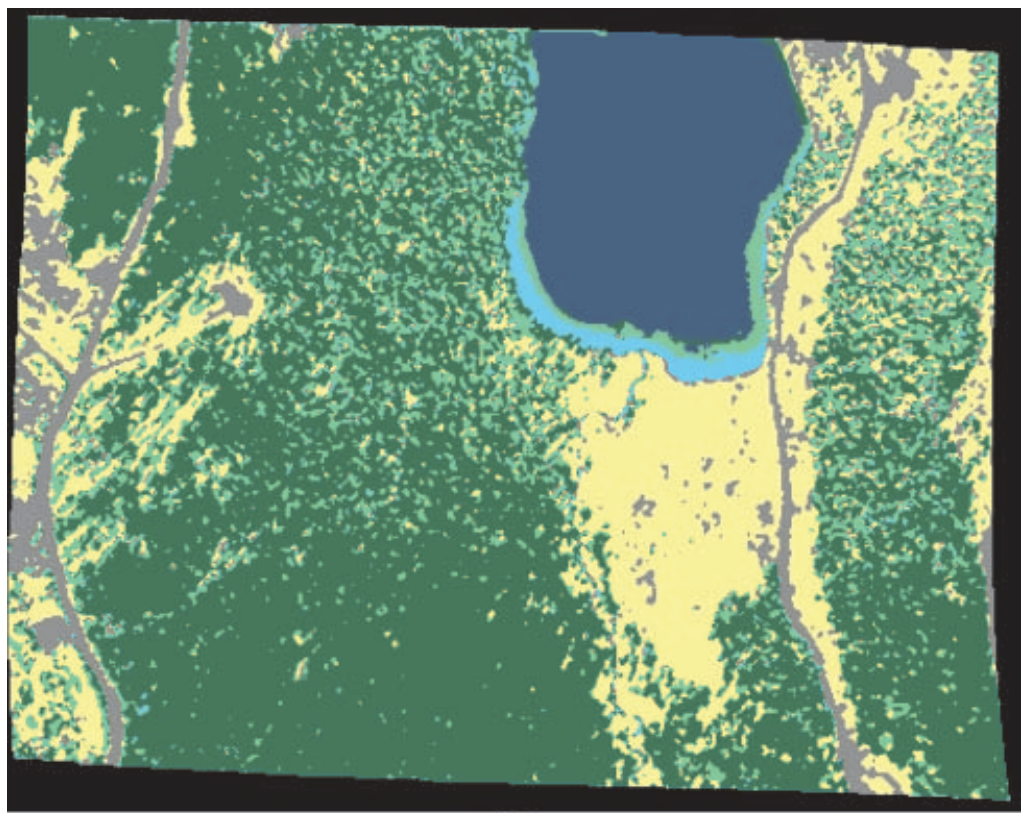

(a)

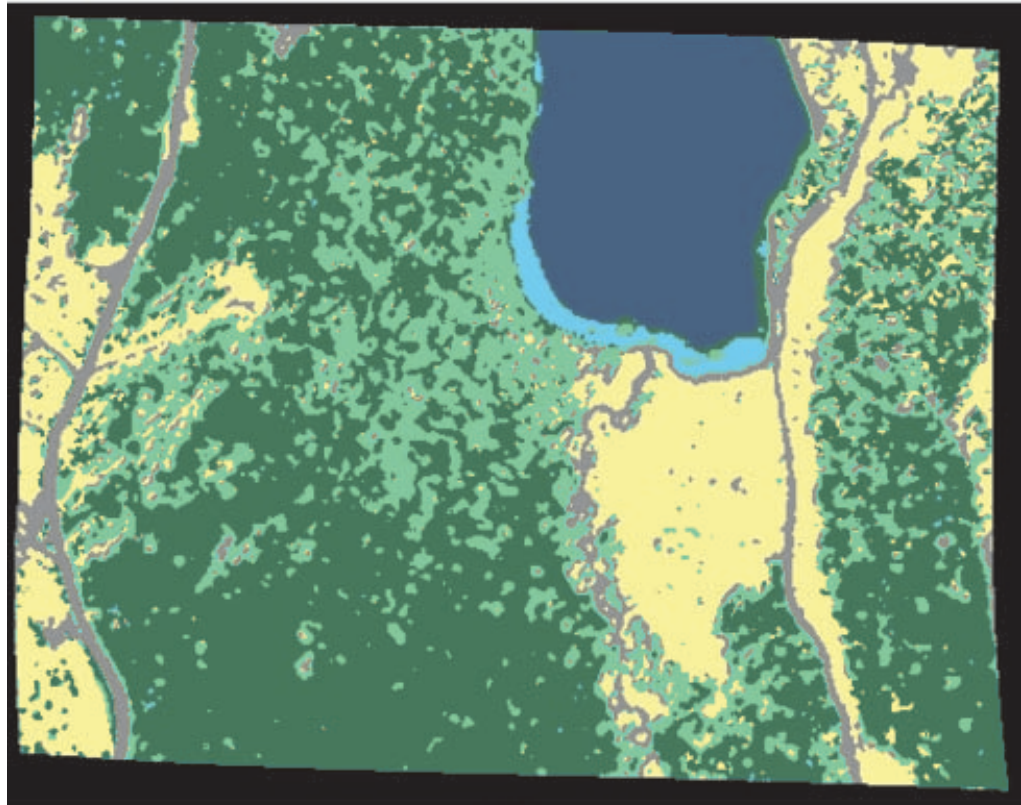

(b)
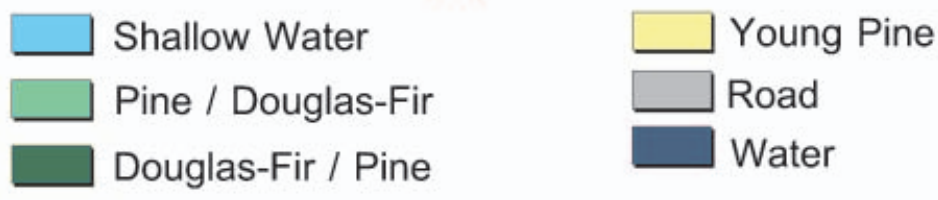

Figure 6. Supervised classification results using only the spectral information $(a)$ and the addition of variance computed for a $5 \times 5$ window $(b)$. 
Table 2. The contingency matrix for the Ben Lake spectral classification. The ground data are plotted in the columns and the classed data in the rows.

\begin{tabular}{|c|c|c|c|c|c|c|c|}
\hline & Water & $\mathrm{DF} /$ pine & Pine/DF & $\begin{array}{c}\text { Shallow } \\
\text { water }\end{array}$ & $\begin{array}{l}\text { Young } \\
\text { pine }\end{array}$ & Road & $\begin{array}{l}\text { User's } \\
\text { accuracy }\end{array}$ \\
\hline Water & 17778 & 0 & 0 & 0 & 0 & 0 & 100.00 \\
\hline DF/pine & 506 & 55339 & 21733 & 156 & 2300 & 174 & 68.99 \\
\hline Pine/DF & 1457 & 14796 & 14292 & 137 & 3034 & 182 & 42.16 \\
\hline Shallow water & 405 & 2725 & 2130 & 1204 & 258 & 40 & 17.81 \\
\hline Young pine & 6 & 3801 & 8102 & 5 & 22535 & 365 & 64.73 \\
\hline Road & 5 & 1526 & 2252 & 23 & 6607 & 3759 & 26.52 \\
\hline \multirow[t]{3}{*}{ Producer's accuracy } & 88.20 & 70.78 & 29.46 & 78.95 & 64.88 & 83.16 & \\
\hline & & & & & Overall & 61.24 & \\
\hline & & & & & Kappa & 0.468 & \\
\hline
\end{tabular}

When the kappa index of agreement was analysed for each class in the classification (figure 8) the class that had the largest improvement was the pine/ Douglas fir class. The difference between the Douglas fir/pine class and the pine/ Douglas fir class was mostly spatial (the pine/Douglas fir class has a coarser texture) rather than spectral. Other classes declined in agreement as the window size was increased, for example the young pine and water classes, but were improved with the multi-spatial procedure. The road class showed a steady decline in accuracy with increasing window size and with the multi-spatial procedure. The shallow water class decreased in accuracy only with the addition of the multi-spatial data.

By performing a classification with only the local variance data, the additional information added by the inclusion of texture was assessed. Figure 9 shows the resulting classification; this image shows that classes like pine/Douglas fir were separable based on texture alone. While some of the classes were not correctly classified using only the textural information, this classification demonstrated that the additional information provided by image texture was beneficial for many classes (table 6).

\subsubsection{Second-order statistics results}

The trends of the classifications incorporating GLCM texture measures were similar to those achieved with local variance. The incorporation of multiple window

Table 3. The contingency matrix from the Ben Lake classification incorporating $5 \times 5$ local variance as a measure of image texture. Improvements in forest stand classification are between 4 and $10 \%$.

\begin{tabular}{|c|c|c|c|c|c|c|c|}
\hline & Water & $\mathrm{DF} /$ pine & Pine/DF & $\begin{array}{c}\text { Shallow } \\
\text { water }\end{array}$ & $\begin{array}{l}\text { Young } \\
\text { pine }\end{array}$ & Road & $\begin{array}{c}\text { User's } \\
\text { accuracy }\end{array}$ \\
\hline Water & 17774 & 0 & 0 & 0 & 0 & 0 & 100.00 \\
\hline DF/pine & 974 & 57939 & 17095 & 125 & 1518 & 112 & 74.51 \\
\hline Pine/DF & 434 & 12537 & 22143 & 273 & 3164 & 231 & 57.10 \\
\hline Shallow water & 704 & 2002 & 416 & 1054 & 22 & 8 & 25.06 \\
\hline Young pine & 0 & 3295 & 5255 & 0 & 24100 & 512 & 72.67 \\
\hline Road & 145 & 1393 & 3347 & 73 & 5516 & 3493 & 25.01 \\
\hline \multirow[t]{3}{*}{ Producer's accuracy } & 88.73 & 75.08 & 45.89 & 69.11 & 70.22 & 80.19 & \\
\hline & & & & & Overall & 68.13 & \\
\hline & & & & & Kappa & 0.56 & \\
\hline
\end{tabular}




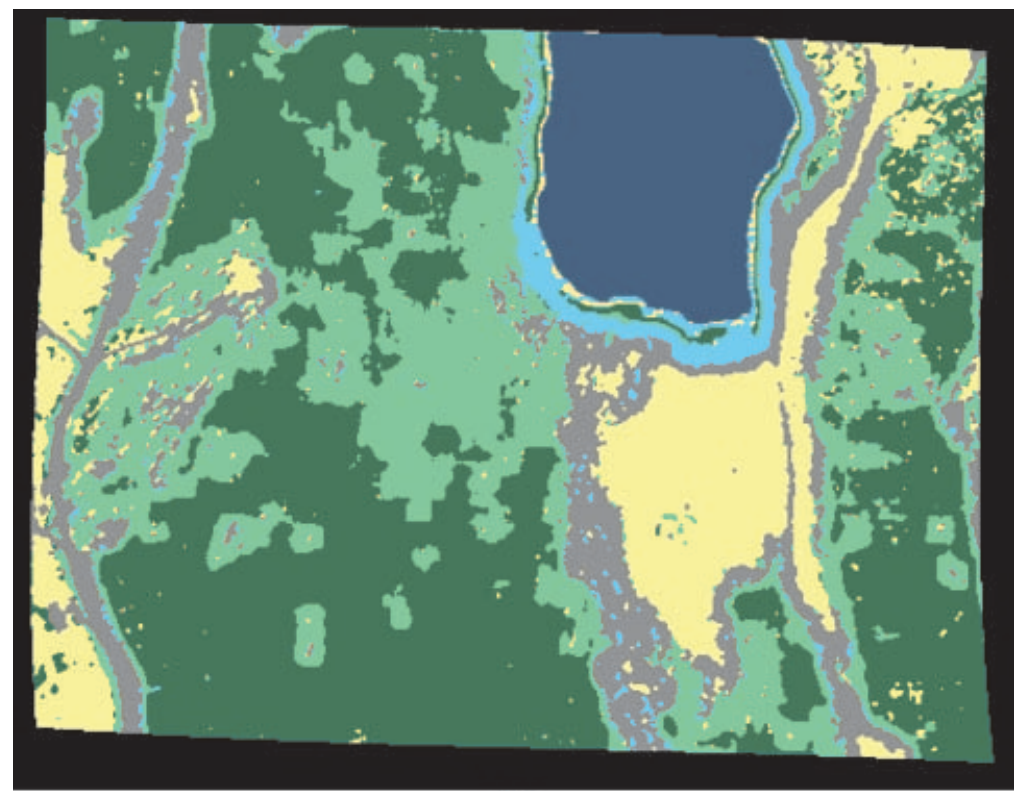

(a)

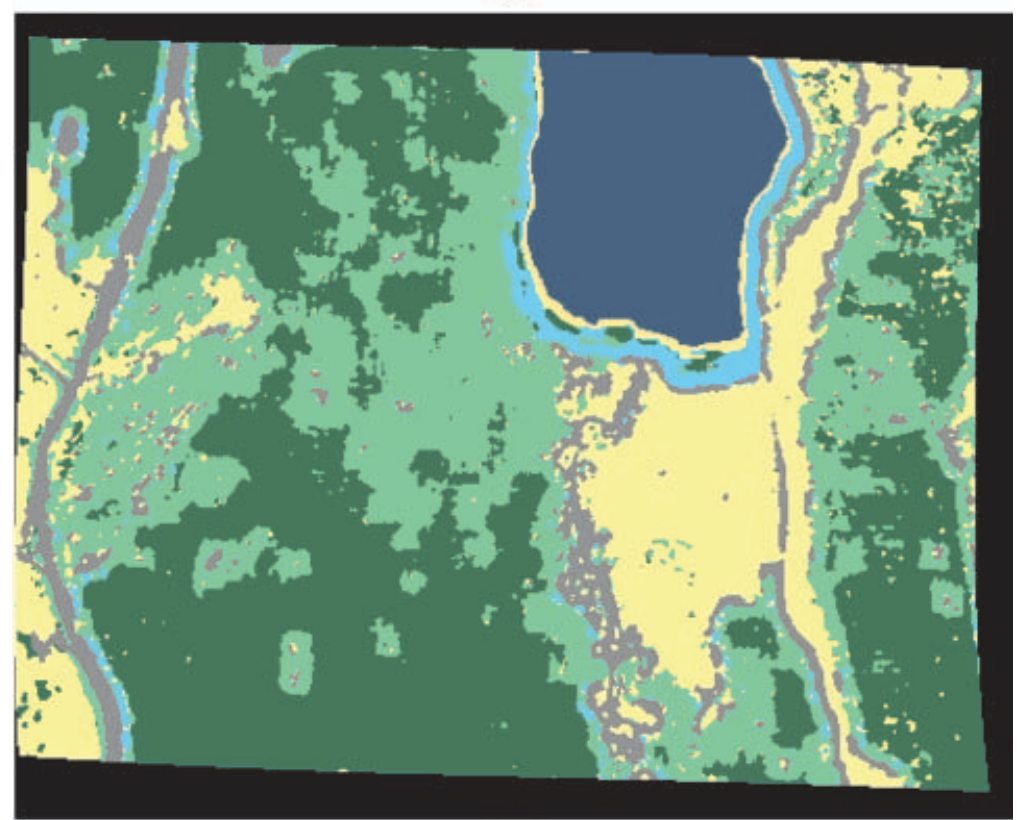

(b)
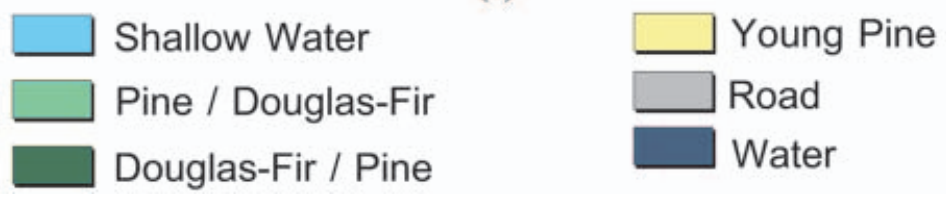

Figure 7. The supervised classification for the infrared $15 \times 15$ variance $(a)$ and infrared variance at all window sizes $(b)$. 
Table 4. The contingency matrix from the Ben Lake classification incorporating $15 \times 15$ local variance. Further improvement of forest stand classification accuracy compared with smaller window sizes, with some decreases in accuracy of groups caused by filter size.

\begin{tabular}{lccccccr}
\hline & Water & DF/pine & Pine/DF & $\begin{array}{c}\text { Shallow } \\
\text { water }\end{array}$ & $\begin{array}{r}\text { Young } \\
\text { pine }\end{array}$ & Road & $\begin{array}{r}\text { User's } \\
\text { accuracy }\end{array}$ \\
\hline Water & 15459 & 0 & 0 & 0 & 0 & 0 & 100.00 \\
DF/pine & 775 & 55209 & 7568 & 25 & 643 & 14 & 85.95 \\
Pine/DF & 556 & 11227 & 28676 & 180 & 2194 & 120 & 66.76 \\
Shallow water & 1892 & 1631 & 2026 & 1274 & 819 & 93 & 16.47 \\
Young pine & 619 & 2654 & 2665 & 1 & 19185 & 530 & 74.78 \\
Road & 66 & 2682 & 6397 & 45 & 8791 & 3137 & 14.85 \\
Producer's accuracy & 79.82 & 75.21 & 60.58 & 83.54 & 60.65 & 80.56 & \\
& & & & & Overall & 69.39 & \\
& & & & & Kappa & 0.59 & \\
\hline
\end{tabular}

sizes with spectral information provided the highest degrees of improvement for the forested classes (figure 10). The class that received the greatest increase as a result of the addition of these texture measures was the pine/Douglas fir class. For the entropy measure the KIA increased 0.21 as the window size increased; the multiscale approach yielded the highest accuracy. Of the second-order statistical measures, entropy and angular second moment texture measures yielded the largest gains in classification accuracy in this study. As expected, the classes that derived the greatest benefit from the addition of the texture were the forested classes. Tables 7 and 8 show the contingency tables for these classifications. A maximum improvement of $35 \%$ was achieved for the multiscale entropy classification of the pine/Douglas fir group over the spectral classification.

This result is similar to the local variance classification results. While the second-order statistical measures provided improvements in accuracy, the gains were not as high as those from the local variance. Overall the classification accuracies for the multiscale GLCM measures were $10 \%$ lower than those of the local variance measure. The forest classes were generally lower for the GLCM measures, but were still improvements over the spectral classification.

Table 5. Contingency matrix from the Ben Lake multiscale variance classification. Further improvement of forest stand classification accuracy and a reduction of the effect of the increasing filter size.

\begin{tabular}{|c|c|c|c|c|c|c|c|}
\hline & Water & $\mathrm{DF} /$ pine & Pine/DF & $\begin{array}{c}\text { Shallow } \\
\text { water }\end{array}$ & $\begin{array}{l}\text { Young } \\
\text { pine }\end{array}$ & Road & $\begin{array}{c}\text { User's } \\
\text { accuracy }\end{array}$ \\
\hline Water & 15292 & 0 & 0 & 0 & 0 & 0 & 100.00 \\
\hline DF/pine & 346 & 56417 & 7235 & 35 & 443 & 5 & 87.49 \\
\hline Pine/DF & 300 & 11799 & 32853 & 264 & 2256 & 137 & 69.01 \\
\hline Shallow water & 1835 & 1407 & 454 & 1166 & 200 & 53 & 22.80 \\
\hline Young pine & 1182 & 1569 & 3131 & 0 & 22373 & 917 & 76.69 \\
\hline Road & 279 & 1418 & 3389 & 60 & 5820 & 2668 & 19.57 \\
\hline \multirow[t]{3}{*}{ Producer's accuracy } & 79.51 & 77.70 & 69.81 & 76.46 & 71.96 & 70.58 & \\
\hline & & & & & Overall & 74.69 & \\
\hline & & & & & Kappa & 0.654 & \\
\hline
\end{tabular}




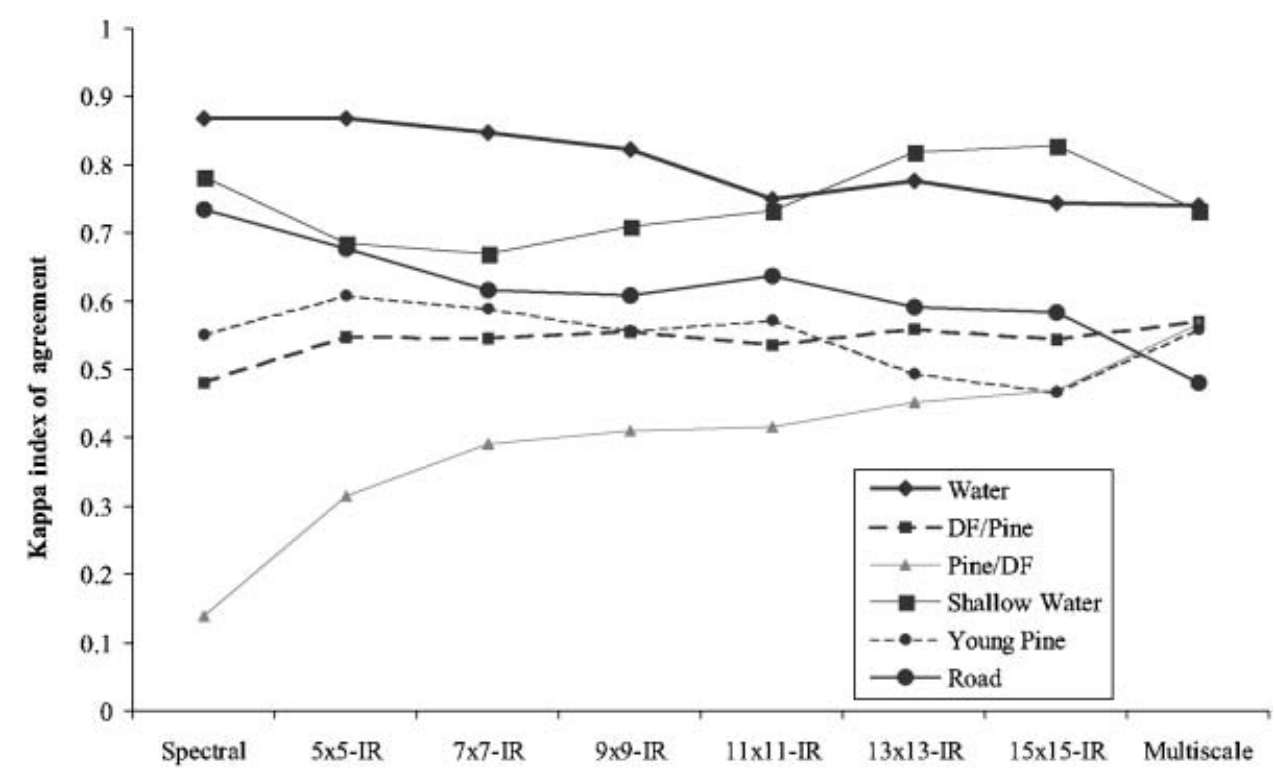

Figure 8. Kappa index of agreement for the Ben Lake study site.

\section{Discussion and conclusions}

The standard approach to texture analysis is to process a single band of spectral information with a fixed size processing window. In this study a multiscale approach was investigated using four different texture measures. The results of this study indicated that when a single band of textural information was added, image classification results would improve. The amount of improvement depended on the relationship between the size of the processing window and the nature of the texture. For example, for areas that displayed lower degrees of spatial variation, smaller window sizes performed better, while for areas with higher degrees of spatial variation, larger windows improved these groups. For all of the texture measures investigated, using more than one window size provided the highest classification accuracies.

Image variance is related to information content in images and therefore determines the ability to extract useful information about the image (Collins and Woodcock 1999). The results indicated that local variance, when with more than one window size and incorporated as a measure of texture in an image classification procedure, can provide a useful measure of image texture and a close approximation to semivariance. While the two measurements were not identical, the similarities provide insight into the utility of multiscale variance as a measure of texture. In this study, local variance provided more accurate classification results than the second-order statistics.

One of the major difficulties with producing texture information from moving windows occurs at the boundary between two different textures. As the window traverses the boundary it analyses a texture at the boundary that is a combination of the two adjacent textures. This boundary problem, also known as the stationarity problem, is most apparent as the window sizes increase and can lead to misclassifications at the edges of features or the over-estimation of classification accuracy for some features (i.e. if the boundary of the feature dilates to encompass the ground data) (Csillag and Kabos 1996). Misclassifications were most common 

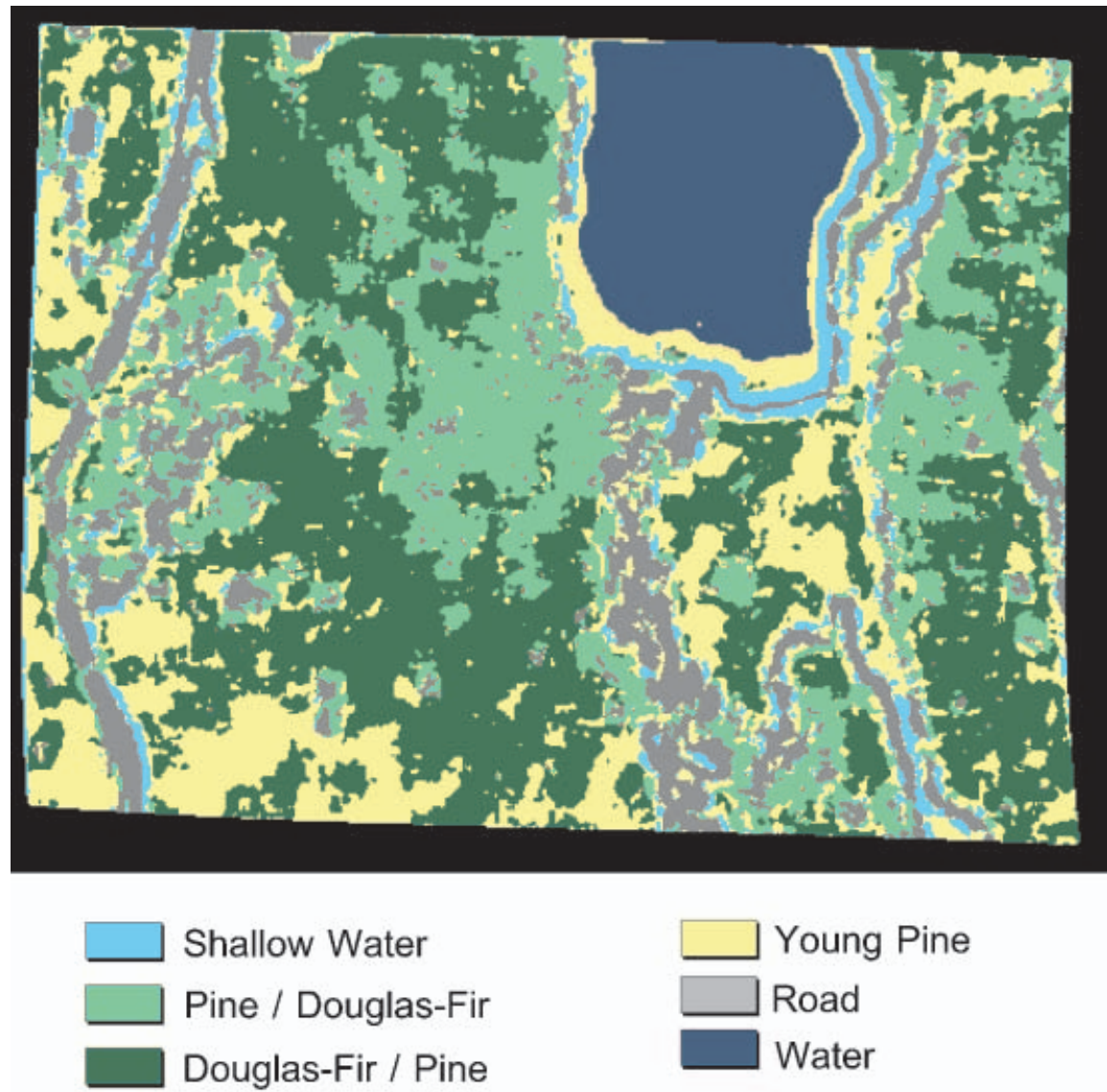

Figure 9. Classification produced from the use of only the variance data from $5 \times 5$ to $15 \times 15$ windows.

at the edges of homogeneous spatial areas. For example, the lake decreased in size and was most accurately represented (as expected) in the classification that used only the spectral data (figure 8).

The classifications produced using the multiple scale approach showed an

Table 6. Contingency matrix from the Ben Lake multiscale classification using only the variance data. This classification demonstrates that for the main forested groups (pine/Douglas fir and Douglas fir/pine) the textural information aided class discrimination.

\begin{tabular}{|c|c|c|c|c|c|c|c|}
\hline & Water & $\mathrm{DF} /$ pine & Pine/DF & $\begin{array}{c}\text { Shallow } \\
\text { water }\end{array}$ & $\begin{array}{l}\text { Young } \\
\text { pine }\end{array}$ & Road & $\begin{array}{c}\text { User's } \\
\text { accuracy }\end{array}$ \\
\hline Water & 15207 & 0 & 0 & 0 & 0 & 0 & 100.00 \\
\hline DF/pine & 25 & 44570 & 6981 & 17 & 6484 & 491 & 76.10 \\
\hline Pine/DF & 57 & 8220 & 26547 & 81 & 2918 & 273 & 69.68 \\
\hline Shallow water & 1215 & 1513 & 1061 & 744 & 2575 & 389 & 9.92 \\
\hline Young pine & 2288 & 15278 & 4980 & 525 & 12307 & 786 & 34.03 \\
\hline Road & 442 & 3029 & 7593 & 158 & 6808 & 1841 & 9.26 \\
\hline \multirow[t]{3}{*}{ Producer's accuracy } & 79.06 & 61.38 & 56.29 & 48.79 & 39.58 & 48.70 & \\
\hline & & & & & Overall & 57.70 & \\
\hline & & & & & Kappa & 0.44 & \\
\hline
\end{tabular}



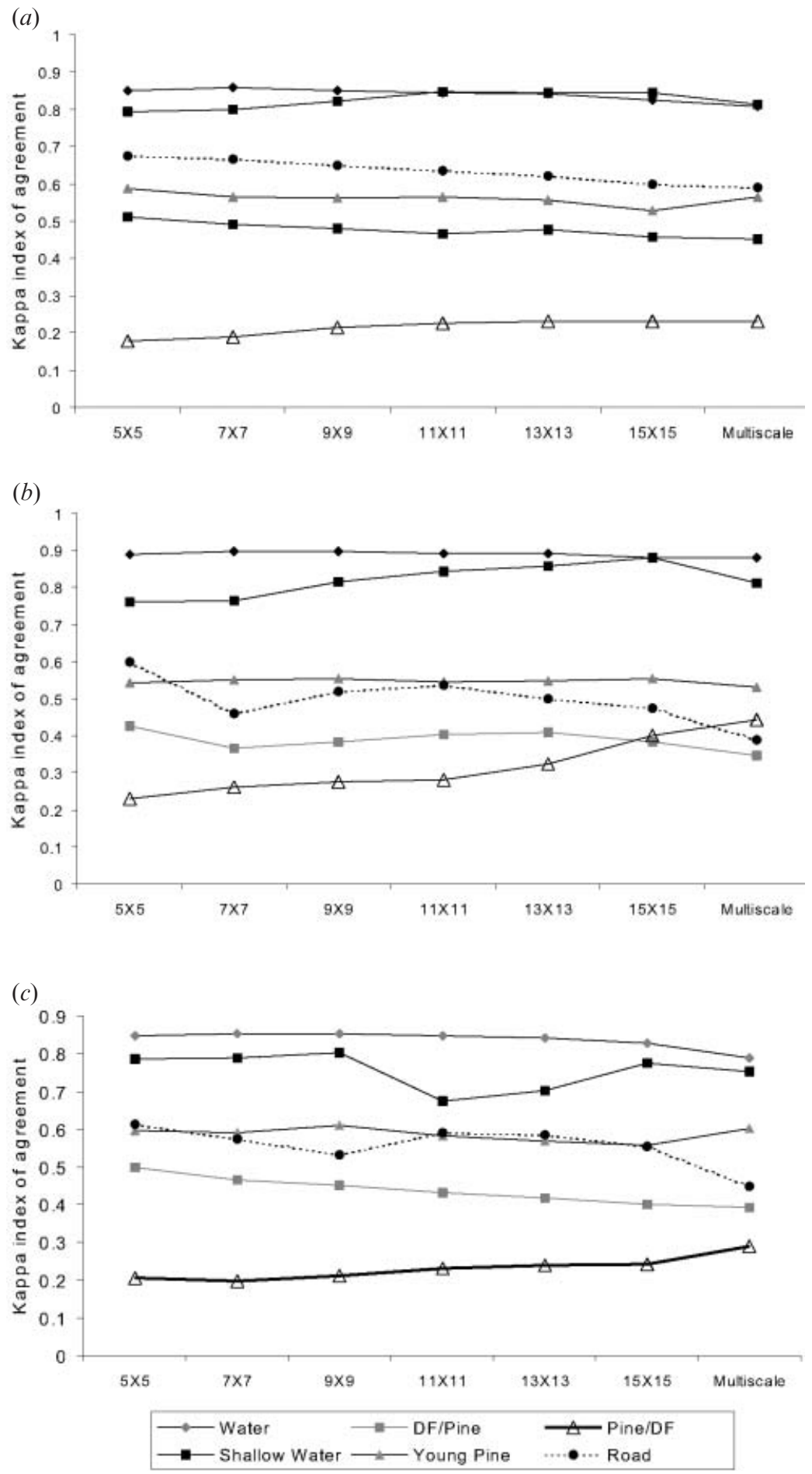

Figure 10. Kappa index of agreement for the second-order statistical texture measures for (a) contrast; (b) entropy; and (c) angular second moment. The accuracy of the classifications generally increased with increasing window sizes with the multiscale approach yielding the largest improvements for the forested classes. 
Table 7. Contingency matrix from the Ben Lake multiscale entropy classification.

\begin{tabular}{|c|c|c|c|c|c|c|c|}
\hline & Water & $\mathrm{DF} /$ pine & Pine/DF & $\begin{array}{c}\text { Shallow } \\
\text { water }\end{array}$ & $\begin{array}{l}\text { Young } \\
\text { pine }\end{array}$ & Road & $\begin{array}{c}\text { User's } \\
\text { accuracy }\end{array}$ \\
\hline Water & 17685 & 0 & 0 & 0 & 0 & 0 & 100.00 \\
\hline $\mathrm{DF} /$ pine & 1 & 38147 & 10888 & 100 & 1173 & 64 & 75.73 \\
\hline Pine/DF & 0 & 27312 & 30689 & 98 & 5660 & 350 & 47.87 \\
\hline Shallow water & 1636 & 1896 & 589 & 1251 & 133 & 19 & 22.65 \\
\hline Young pine & 45 & 5411 & 3742 & 69 & 21041 & 1037 & 67.13 \\
\hline Road & 0 & 637 & 1452 & 7 & 3647 & 2374 & 29.25 \\
\hline \multirow[t]{3}{*}{ Producer's accuracy } & 91.32 & 51.97 & 64.80 & 82.03 & 66.47 & 61.76 & \\
\hline & & & & & Overall & 62.76 & \\
\hline & & & & & Kappa & 0.49 & \\
\hline
\end{tabular}

Table 8. Contingency matrix for the Ben Lake multiscale angular second moment classification.

\begin{tabular}{lrrrrrrr}
\hline & & & & Shallow \\
& Water & DF/pine & Pine/DF & $\begin{array}{c}\text { Young } \\
\text { pine }\end{array}$ & Road & $\begin{array}{r}\text { User's } \\
\text { accuracy }\end{array}$ \\
\hline Water & 16224 & 0 & 0 & 0 & 0 & 0 & 100.00 \\
DF/pine & 1965 & 47337 & 18666 & 119 & 2887 & 200 & 66.51 \\
Pine/DF & 625 & 18441 & 21140 & 236 & 2084 & 115 & 49.58 \\
Shallow water & 552 & 1513 & 786 & 1156 & 18 & 6 & 28.68 \\
Young pine & 0 & 5599 & 5722 & 2 & 23829 & 1121 & 65.69 \\
Road & 1 & 513 & 1046 & 12 & 2836 & 2402 & 35.27 \\
Producer's accuracy & 83.77 & 64.49 & 44.64 & 75.80 & 75.28 & 62.49 & \\
& & & & & Overall & 63.27 & \\
& & & & & Kappa & 0.49 & \\
\hline
\end{tabular}

improvement (up to $9 \%$ for kappa between the $15 \times 15$ variance and the multiscale variance classification) over classifications that only added a single spatial band of information. For this image, the kappa index of agreement indicated that the class that benefited the most from the addition of the multiscale variance was the pine/ Douglas fir class for all of the texture measures. The addition of texture to this class (regardless of how it was included) resulted in improved classification accuracies. This class is spatially different from the Douglas fir/pine, not spectrally different.

A multiscale approach yielded the best combination for these groups in an overall perspective regardless of which method was used to produce the texture measure. The multiscale variance measure of image texture achieved the highest overall classification results for this study (74.69\%). The highest accuracy achieved for the second-order statistics was $63.27 \%$ for the multiscale angular second moment measure. The differences in accuracy between the local variance measure and the second-order statistical measures were greatest for the main forest stands (Douglas fir/pine and pine/Douglas fir). While the local variance techniques improved the classification of both groups, the second-order statistics improved one or the other, but not both simultaneously.

Multiscale local variance provided additional discriminating power for separating forest stands that differ in terms of their structural properties. This multiscale local variance approach to image texture processing represents a simple technique for the addition of textural information. The local image variance approach generated better classification results than the second-order statistics used in this study. 
For images that contain complex spatial structures, there is no 'optimum' window size to extract the textural information. For these types of data, a processing technique that combines multiple scales of information performs best. As the spatial resolution of remotely sensed data increases, multiscale processing techniques may provide better overall performance in texturally complex environments.

\section{Acknowledgments}

This research was partially funded by Forest Renewal British Columbia. The authors would like to thank Dr D. R. Peddle and Dr P. Gong for their valuable comments.

\section{References}

AtKinson, P. M., 1993, The effect of spatial resolution on the experimental variogram of airborne MSS imagery. International Journal of Remote Sensing, 14, 1005-1011.

BARBER, D. G., and LEDREW, E. F., 1991, SAR sea ice discrimination using texture statistics: a multivariate approach. Photogrammetric Engineering and Remote Sensing, 50, 385-395.

BRITISH COLUMBIA COMMISSION ON RESOURCES AND ENVIRONMENT, 1994, Cariboo-Chilcotin Land Use Plan (Victoria, British Columbia: Province of British Columbia), vol. 1.

Chica-Olmo, M., and Abarca-Hernandez, F., 2000, Computing geostatisitcal image texture for remotely sensed data classification. Computers and Geosciences, 26, 373-383.

Cohen, W. B., Spies, T. A., and Bradshaw, G. A., 1990, Semivariograms of digital imagery for analysis of conifer canopy structure. Remote Sensing of Environment, 34, 167-178.

Collins, J. B., and Woodcock, C. E., 1999, Geostatistical estimation of resolutiondependant variance in remotely sensed images. Photogrammetric Engineering and Remote Sensing, 65, 41-50.

Cross, G. R., and JAIN, A. K., 1983, Markov random field texture models. IEEE Transactions on Pattern Analysis and Machine Intelligence, 5, 25-39.

Csillag, F., and KaBOS, S., 1996, Hierarchical decomposition of variance with applications in environmental mapping based on satellite images. Mathematical Geology, 28, 385-405.

Curran, P., 1988, The semivariogram in remote sensing: An introduction. Remote Sensing of Environment, 32, 493-507.

DesouzA, P., 1982, Texture recognition via autoregression. Pattern Recognition, 15, 471-475.

Dobbertin, M., and Biging, G., 1996, A simulation study of the effect of scene autocorrelation, training sample size and sampling method on classification accuracy. Canadian Journal of Remote Sensing, 22, 360-367.

Du Buf, J. M. H., Kardan, M., and SpanN, M., 1990, Texture feature performance for image segmentation. Pattern Recognition, 23, 291-309.

EYTON, J. R., 1993, Urban land use classification and modelling using cover-type frequencies. Applied Geography, 13, 111-121.

Franklin, S. E., and MCDERMID, G. J., 1993, Empirical relations between digital SPOT HRV and CASI spectral response and lodgepole pine (Pinus contorta) forest stand parameters. International Journal of Remote Sensing, 14, 2331-2348.

Franklin, S. E., and Peddle, D. R., 1987, Texture analysis of digital image data using spatial co-occurrence. Computers and Geosciences, 13, 293-311.

Franklin, S., and PedDle, D., 1989, Spectral texture for improved class discrimination in complex terrain. International Journal of Remote Sensing, 10, 1437-1443.

Franklin, S., and Peddle, D., 1990, Classification of SPOT HRV imagery and texture features. International Journal of Remote Sensing, 11, 551-556.

Franklin, S. E., Wulder, M. A., and Gerylo, G. R., 2001, Texture analysis of IKONOS panchromatic data for Douglas-fir forest age class separability in British Columbia. International Journal of Remote Sensing, 22, 2627-2632.

Gong, P., and Howarth, P. J., 1992, Frequency-based contextual classification and grey 
level vector reduction for land-use identification. Photogrammetric Engineering and Remote Sensing, 58, 423-437.

Gong, P., Marceau, D. J., and Howarth, P. J., 1992, A comparison of spatial feature extraction algorithms for land-use classification with SPOT HRV data. Remote Sensing of Environment, 40, 137-151.

Haralick, R. M., 1979, Statistical and structural approaches to texture. Proceedings of the IEEE, 67, 786-804.

Haralick, R. M., Shaunmmugam, K., and Dinstein, I., 1973, Textural features for image classification. IEEE Transactions on Systems, Man, and Cybernetics, 3, $610-621$.

Hay, G. J., and Niemann, K. O., 1994, Visualizing 3-D texture: A three-dimensional structural approach to model forest texture. Canadian Journal of Remote Sensing, 20, 90-101.

Hsu, S., 1980, Texture perception and the RADC/Hsu texture feature extractor. Photogrammetric Engineering and Remote Sensing, 46, 1051-1058.

JENSEN, J. R., 1982, Detecting residential land-use development at the urban fringe. Photogrammetric Engineering and Remote Sensing, 48, 629-643.

Jensen, J. R., 1996, Introductory Digital Image Processing: A Remote Sensing Perspective, 2nd edn (Englewood Cliffs, New Jersey: Prentice-Hall).

JULESZ, B., 1962, Visual pattern discrimination. IRE Transactions on Information Theory, $\mathbf{8}$, 84-92.

Jupp, D. B., Strahler, A. H., and Woodcock, C. E., 1988, Autocorrelation and regularization in digital images I. Basic theory. IEEE Transactions on Geoscience and Remote Sensing, 26, 463-473.

LARK, R. M., 1996, Geostatistical description of texture on an aerial photograph for discriminating classes of land cover. International Journal of Remote Sensing, 17, 2115-2133.

Lillesand, T. M., and Kiefer, R. W., 2000, Remote Sensing and Image Interpretation, 4th edn (New York: Wiley).

MAO, J., and JAIN, A. K., 1992, Texture classification and segmentation using multiresolution simultaneous autoregressive models. Pattern Recognition, 25, 173-188.

Miranda, F. P., MacDonald, J. A., and CARR, J. R., 1992, Application of the semivariogram textural classifier (STC) for vegetation discrimination using SIR-B data of Borneo. International Journal of Remote Sensing, 13, 2349-2354.

PANNATIER, Y., 1996, Variowin: Software for spatial data analysis in 2D. (New York: Springer-Verlag).

Peddle, D. R., 1995, Knowledge formulation for supervised evidential classification. Photogrammetric Engineering and Remote Sensing, 61, 409-417.

Peddle, D. R., and Franklin, S. E., 1991, Image texture processing and data integration for surface pattern discrimination. Photogrammetric Engineering and Remote Sensing, 57, 413-420.

ReED, T., and Du BuF, J. M. H., 1993, A review of recent texture segmentation and feature extraction techniques. Computer Vision, Graphics, and Image Processing: Image Understanding, 57, 359-372.

Roberts, A. C. B., 1995, Integrated MSV airborne remote sensing. Canadian Journal of Remote Sensing, 21, 214-224.

Rosenfield, G., and FitZPATRICK-Lins, K., 1986, A coefficient of agreement as a measure of thematic classification accuracy. Photogrammetric Engineering and Remote Sensing, 52, 223-227.

RyHerd, S., and Woodcock, C. E., 1996, Combining spectral and texture data in the segmentation of remotely sensed images. Photogrammetic Engineering and Remote Sensing, 62, 181-194.

SAli, E., and WolfSON, H., 1992, Texture classification in aerial photographs and satellite data. International Journal of Remote Sensing, 13, 3395-3408.

Schachter, B. J., Rosenfeld, A., and Davis, L. S., 1978, Random mosaic models for textures. IEEE Transactions on Systems, Man, and Cybernetics, 8, 694-702.

St-Onge, B., and CAvayAs, F., 1995, Estimating forest stand structure from high resolution imagery using the directional variogram. International Journal of Remote Sensing, 16, 1999-2021.

TreITZ, P., 2001, Variogram analysis of high spatial resolution remote sensing data: An 
examination of boreal forest ecosystems. International Journal of Remote Sensing, 22, 3895-3900.

Van Gool, L., Dewaele, P., and Oosterlinck, A., 1985, Texture analysis annon 1983. Computer Vision, Graphics, and Image Processing, 29, 336-357.

WANG, L., and HE, D. C., 1990, A new statistical approach for texture analysis. Photogrammetric Engineering and Remote Sensing, 56, 61-66.

Weszka, J. S., Dyer, C. R., and Rosenfeld, A., 1976, A comparative study of texture measures for terrain classification. IEEE Transactions on Systems, Man, and Cybernetics, 6, 269-285.

WhARTON, S. W., 1982, A contextual classification method for recognizing land use patterns in high resolution remotely sensed data. Pattern Recognition, 15, 317-324.

Woodcock, C. E., and Strahler, A. H., 1987, The factor of scale in remote sensing. Remote Sensing of Environment, 21, 311-332.

Woodcock, C. E., Strahler, A. H., and JupP, D., 1988a, The use of variograms in remote sensing: I. Scene models and simulated images. Remote Sensing of Environment, 25, 323-348.

Woodcock, C. E., Strahler, A. H., and Jupp, D., 1988b, The use of variograms in remote sensing: II. Real digital images. Remote Sensing of Environment, 25, 348-379.

Wulder, M., Lavigne, M., and Franklin, S., 1996, High spatial resolution optical image texture for improved estimation of forest stand leaf area index. Canadian Journal of Remote Sensing, 22, 441-449.

Wulder, M., Ledrew, E. F., Franklin, S. E., and Lavigne, M. B., 1998, Aerial image texture information in the estimation of northern deciduous and mixed wood leaf area index (LAI). Remote Sensing of Environment, 64, 64-76.

Xu, B., Gong, P., Seto, E., and Spear, R., 2003, Comparison of gray level reduction schemes with a revised texture spectrum method for land-use classification using IKONOS imagery. Photogrammetric Engineering and Remote Sensing, 69, 529-536. 